\title{
From their own perspective - constraints in the Polio Eradication Initiative: perceptions of health workers and managers in a district of Pakistan's Punjab province
}

Muhammad Umair Mushtaq ${ }^{1 *}$, Ubeera Shahid ${ }^{1}$, Muhammad Ashraf Majrooh ${ }^{1}$, Mushtaq Ahmad Shad², Arif Mahmood Siddiqui', Javed Akram

\begin{abstract}
Background: The success of the Global Polio Eradication Initiative was remarkable, but four countries Afghanistan, Pakistan, India and Nigeria - never interrupted polio transmission. Pakistan reportedly achieved all milestones except interrupting virus transmission. This paper describes the perceptions of health workers and managers regarding constraints in the Polio Eradication Initiative (PEI) to ultimately provide evidence for designing future interventions.
\end{abstract}

Methods: A qualitative cross-sectional study using focus group discussions and in-depth interviews was conducted in the Nankana Sahib District of Pakistan's Punjab province. Study subjects included staff at all levels in the PEl at district headquarters, in all 4 tehsils (sub-districts) and at 20 randomly selected primary health centers. In total, 4 FGD and 7 interview sessions were conducted and individual session summary notes were prepared and later synthesized, consolidated and subjected to conceptual analysis.

Results: The main constraints identified in the study were the poor condition of the cold chain in all aspects, poor skills and a lack of authority in resource allocation and human resource management, limited advocacy and communication resources, a lack of skills and training among staff at all levels in the PEI/EPI in almost all aspects of the program, a deficiency of public health professionals, poor health services structure, administrative issues (including ineffective means of performance evaluation, bureaucratic and political influences, problems in vaccination areas and field programs, no birth records at health facilities, and poor linkage between different preventive programs), unreliable reporting and poor monitoring and supervision systems, limited use of local data for interventions, and unclear roles and responsibilities after decentralization.

Conclusion: The study highlights various shortcomings and bottlenecks in the PEI, and the barriers identified should be considered in prioritizing future strategies.

\section{Background}

Polio has crippled the human race for centuries, the first reports of the disease being made as early as 1350 [1]. In 1988, when polio was endemic in more than 125 countries affecting about 1000 children each day, the Global Polio Eradication Initiative (GPEI) was launched after a World Health Assembly resolution called for the

\footnotetext{
* Correspondence: umairmushtaq_aimc@yahoo.com

${ }^{1}$ Research Society, Allama Iqbal Medical College, Lahore, Pakistan

Full list of author information is available at the end of the article
}

eradication of polio by the year 2000 [2,3]. The success of the initiative was remarkable and nearly 5 million children were protected from being paralyzed by 2003 [4], however, four countries - Afghanistan, Pakistan, India and Nigeria - never interrupted transmission of the wild polio virus, and re-infection in twenty six countries in 2006-07 raised many concerns regarding the feasibility of polio eradication. By the end of 2007, polio incidence had decreased by $35 \%$ and polio transmission had stopped in all but 6 re-infected countries [5], yet 
polio eradication seems illusory as the endemic countries are missing polio eradication targets and 1648 cases were reported worldwide in 2008 [6].

Pakistan has a population of about 160 million and only $2 \%$ of GDP is spent on health $[7,8]$. Per 10,000 people, there are 8 physicians, mainly clustered in urban areas, and 4 community health workers. Public health care services are delivered by the provincial Departments of Health and Federal Government is concerned with planning and policy making. A district health system was introduced in 2001, and now districts are independent in administrative and financial matters regarding health care [9]. Pakistan adopted the Polio Eradication Initiative (PEI) within the Expanded Program on Immunization (EPI) in 1994 [10]. In Pakistan, PEI is managed at central level by the National EPI Cell, housed in the National Institute of Health at the Ministry of Health. It is concerned with planning, policy making, and the procurement of vaccines, the provision of technical guidance and mid-level management training, monitoring and evaluation, and coordination with international agencies. At provincial level, the PEI/EPI is managed by the Director of Health Services (EPI) in the office of the Director General of Health Services. He is concerned with the distribution of vaccines, supervision, monitoring and training. The Executive District Officer Health (or District Health Officer in some provinces) is the chief of the district health department and the pivotal person in managing the PEI/EPI with the assistance of a team of officials, explained later in the section on methods.

The number of polio cases in Pakistan decreased remarkably to 32 by 2007, including 19 WPV type 1 and 13 WPV type 3 cases with the virus found in only 18 of the 120 districts. But polio resurged in 2008, infecting 49 districts with 118 cases, including 81 WPV type 1 and $37 \mathrm{WPV}$ type 3 cases - the highest number in the previous six years $[4,6,10,11]$. In 2009, 89 cases from 32 districts were reported and 15 high risk districts were identified, 9 having persistent transmission and 6 repeatedly infected districts, and district specific plans were developed [12]. Unprecedented support from the highest leadership was achieved, including the Prime Minister's Polio Action Plan in February 2009, which focuses on inter-sectoral coordination but it needs to be replicated at provincial and district levels and engage all sectors of civil administration and society [12]. Pakistan failed to interrupt polio virus transmission despite reportedly achieving the targets set in the GPEI strategic plan, including intensified mass immunization activities (national/sub-national immunization days, NIDs/SNIDs), mop-up campaigns within 4 weeks of every case, and certification standards for surveillance and laboratories. However, the Global Alliance for Vaccination and
Immunization (GAVI) target of $90 \%$ national routine oral polio vaccine (OPV) coverage (current coverage of $83 \%$ ) and $80 \%$ routine OPV coverage in every district by 2010 could not be reached $[2,5,8,13]$. The major factors contributing to the failure to interrupt virus transmission and the re-circulation of the virus were probably cross-border transmission from Afghanistan, poor commitment at the district level for polio eradication, subdistrict coverage gaps, low routine coverage, operational weaknesses in the quality of services and large numbers of children missed during NIDs/SNIDs. Punjab has demonstrated the capacity to interrupt indigenous polio virus circulation and maintain the interruption for almost 2 years, but due to a convergence of factors, including insufficient EPI coverage, a reduction in the number of vaccination campaigns, and an influx of population from insecure areas having low immunity resulted in an environment favorable for the importation associated outbreak of polio in 2008 that continued in 2009 [12]. Ensuring a uniformly high routine OPV coverage and the high quality immunization campaigns, and sustaining the attainable achievements are the major challenges. The situation merits urgent attention.

As health programs mature, large-scale or national surveys become less useful. Instead, data from smallscale studies is required to evaluate different aspects of a program [14]. An evaluation of the PEI in one district of Pakistan's Punjab Province was conducted to establish a valid and reliable estimate for the effectiveness of polio eradication services and to provide scientific evidence for prioritizing future strategies. Both quantitative and qualitative methods were employed to provide an indepth analysis of the factors contributing to failure to achieve polio eradication. The findings from the quantitative work that followed lot quality assurance sampling (LQAS) have been presented elsewhere and revealed low OPV coverage, both routine and during NIDs, and the poor quality of logistics management, monitoring systems and NIDs service delivery [15]. The main findings were [15]: five out of twenty lots were rejected for unacceptably low routine OPV coverage and the validity of coverage was questionable to the extent that all lots were rejected; among the $54 \%$ who were able to present immunization cards, only $74 \%$ had valid immunization; all of the 20 lots were rejected for poor compliance in logistics management and quality of monitoring systems; the mean compliance score and compliance percentage for logistics management were $5.4 \pm 2.0$ (scale 0-9) and $59.4 \%$, while those for quality of monitoring systems were $3.3 \pm 1.2$ (scale $0-6$ ) and $54.2 \%$; 15 out of 20 lots were rejected for unacceptably low NID coverage by finger-mark; and all of the 20 lots were rejected for poor NID service delivery (mean compliance score $=11.7 \pm$ 2.1 [scale 0-16], compliance percentage $=72.8 \%$ ). 
Very few studies have been conducted to reflect perspectives of managers and providers in immunization programs, focusing specifically on polio eradication [16-20]. The perceptions of those directly involved in the field can provide valuable information for designing future interventions. Qualitative assessment provides conceptual analysis, helping to understand the meaning of human social arrangements, program management services and decision making processes, and conveys to the policy makers the experiences of those executing the policies and those that are affected by the policies [21]. Therefore, the qualitative analysis was included in the evaluation with the aim of providing an in-depth performance analysis, and exploring the perceptions of health workers and managers regarding constraints in the PEI with reference to: 1) program resources and logistics, 2) technical aspects, 3) program operation, management and organization, and 4) monitoring, evaluation and feedback.

\section{Methods}

\section{Study Area/Setting}

The study was conducted in the Nankana Sahib District of Pakistan's Punjab Province. Punjab is the most populous province of Pakistan with 93 million inhabitants. There are 2,800 first level care facilities in the province, including about 300 rural health centers (RHCs) located in suburban areas and 2,500 basic health units (BHUs) located in rural areas, to provide primary health care services, including immunization [22,23]. Nankana Sahib District is situated in the central part of Punjab with an area of 2719 square kilometers. The District Department of Health provides curative, preventive and promotive services to 1.8 million inhabitants of the district, both rural and urban, with about 100 health facilities and 1800 health personnel. The district is divided into 4 tehsils (sub-districts), namely Nankana Sahib, Shahkot, Sangla Hill and Safdarabad, and 68 union councils. (Department of Health, District Nankana Sahib: Unpublished administrative data, 2009)

In Pakistan's Punjab province, the Executive District Officer Health $(\mathrm{EDOH})$ is the head of the district health department and is assisted by the District Officer Health (DOH) for public health services. The PEI/EPI at district level is coordinated by the District EPI Focal Person, the District Polio Surveillance Coordinator (DSC) and the District Superintendent of Vaccination (DSV). At tehsil (sub-district) level, the Deputy District Officer of Health $(\mathrm{DDOH})$ is responsible for public health services and the PEI/EPI is supervised by Assistant Superintendents of Vaccination (ASVs) and Inspectors of Vaccination (IVs). At town level, health care services are provided by a rural health centre (RHC) under the charge of a Senior Medical Officer (SMO) but no official is available there to over-see PEI/EPI activities. At union council level, the Medical Officer (MO) at basic health units (BHU) provides health care services and supervises vaccination. The Vaccinator is the pivotal person responsible for vaccination at union council level. In Nankana Sahib District, sanitation and communicable disease control (CDC) personnel, including the District Sanitary Inspector (DSI) and the Communicable Disease Control Officer (CDCO) at district level, the Tehsil Sanitary Inspector (TSI) and the CDC Inspector (CDCI) at tehsil (sub-district) level, the Sanitary Inspector (SI) and the CDC supervisor at the union council, are deputed for PEI/EPI activities along with their routine work. In addition, Lady Health Workers (LHWs) working under the National Program for Family Planning and Primary Health Care (NP for FP \& PHC) are also deputed with vaccinators to improve vaccination coverage.

\section{Study Design and Sample}

A qualitative cross-sectional study was conducted using Focus Group Discussions (FGDs) and In-Depth Interviews that have been extensively used in qualitative research in health care [21]. Qualitative design was followed to gain a more in-depth insight into the constraints in the PEI perceived by health workers and managers in a district. Qualitative methodology has been used commonly in investigating complex health care situations [24-29]. It helps to conceptualize the investigated area and its strength to assess processes and gain insight to the views of participants has been noted $[26,30]$. A complex intervention may operate differently in practice from the original intention and qualitative research can address how an intervention is used in practice [31].

\section{FGDs for vaccinators (providers)}

The target group was vaccinators. Two FGD sessions were organized. Each session involved 10 participants and a total of 20 vaccinators from 20 randomly selected primary health centers out of the 70 primary health centers in the district participated (RHCs at Syedwala, Warburton and Sangla Hills, and BHUs at Islamnagar, Youngsonabad, Chak 13 Randher, Chak 17 Karial, Bahawalkot, Nabi Pur Piran, Chak Hyderabad, Machhora, Marrar Chak 41, Marrar Chak 42, Marh Baluchan, Kot Rehmat Khan, Pakhariwal, Amer Kot, Qila Mir Zaman, Bahalike and Mandhiala).

FGDs for primary health center in-charges and tehsil (subdistrict) managers

The target group included in-charges of the primary health centers and tehsil managers. Tehsil managers included ASV and TSI at Tehsil Nankana Sahib. The posts of DDOH, IV and CDCI in all the four tehsils and the posts of ASV and TSI in the other three tehsils of the district were lying vacant. Two FGD sessions were 
organized. Session 1 involved 12 participants and session 2 involved 10 participants, and a total of 2 tehsil PEI/ EPI managers and 20 in-charges of the primary health centers (3 RHCs and 17 BHUs named above) participated in the sessions.

\section{In-Depth Interviews of district managers}

In-depth interviews were conducted with district managers of the PEI/EPI. The participants included: the EDOH, DOH, District EPI Focal Person, DSC, DSV, CDCO and DSI of the Nankana Sahib District.

\section{Data Collection}

The guidelines for conducting the FGDs and interviews were developed and pre-tested and then revised based upon the feedback from the participants. The sessions were semi-structured but open discussion was encouraged. We probed participants on the following topics: program resources and logistics, technical aspects, program operation, management and organization, and monitoring, evaluation and feedback.

In total, 4 FGDs and 7 interviews were carried out. The FGD and interview sessions were conducted by a two member team that included a sociologist who acted as the facilitator, and a trained medical student who served to record the session and assist as required. The training and orientation session for the data collection team was held in Allama Iqbal Medical College, Lahore, Pakistan. The facilitator was responsible for recruitment, physical arrangements, conducting each session, analysis and reporting of the session. During each session, the facilitator made introductions, built rapport, encouraged discussion, controlled the rhythm, avoided being placed in the role of expert and summarized and concluded the session. The recorder kept a record of the contents of the discussion as well as emotional reactions and other important aspects. Individual session summary notes were prepared immediately after the completion of each FGD session and/or interview, and later synthesized, consolidated and subjected to content analysis. Data was kept confidential by assigning codes to the session notes, preventing unauthorized access and keeping the data secure and sealed after analysis by the Principal Investigator.

Verbal informed consent from the respondents was deemed sufficient due to the non-invasive nature of the study, but written permission from all the participants was taken prior to start of each $\mathrm{FGD} /$ interview session. Approvals for the study were granted by the Ethical Review Board of Allama Iqbal Medical College, Lahore, Pakistan and the Department of Health, Nankana Sahib District, Punjab, Pakistan.

\section{Data Analysis}

Qualitative analysis of data is characterized by the development and manipulation of concepts [21]. Good practice for qualitative research, including theoretical sampling, validation and conceptual analysis was followed [32-35]. Data was analyzed by manual content analysis. The primary tasks were the inspection and coding and classification of data, and later subjecting it to conceptual analysis and development of typologies that convey the range of views, responses, or arrangements under study. Primary emphasis was paid to elucidating areas of thematic importance and exploring major constraints in failure to achieve polio eradication as perceived by the providers and managers of PEI/EPI services. The analysis was aimed at identifying technical, organizational and behavioral issues. After each session, the facilitator and recorder met to review and complete the notes taken during the session and to evaluate how the session went. A full report of the session was then prepared that reflected the session as completely as possible, using the participants' own words. Key statements, ideas and attitudes expressed on each topic of the session were listed. After the transcript of the session was prepared, the statements were coded, using the left margins. Any additional comments were written in the right margins. The questions and their responses were categorized according to the objectives to summarize the results. Draft reports of each session were developed in which responses were noted as per pre-established guidelines. A consolidated qualitative report was synthesized following the completion of all qualitative assessments.

\section{Results}

The main constraints identified by the respondents were the poor condition of the cold chain in all aspects, poor skills and a lack of authority in resource allocation and human resource management, limited advocacy and communication resources, a lack of skills and training among staff at all levels in the PEI/EPI in almost all aspects of the program, a deficiency of public health professionals, poor health services structure, administrative issues (including ineffective means of performance evaluation, bureaucratic and political influences, problems in vaccination areas and field programs, no birth records at health facilities, and poor linkage between different preventive programs), unreliable reporting and poor monitoring and supervision systems, limited use of local data for interventions, and unclear roles and responsibilities after decentralization.

\section{Program resources and logistics}

The respondents indicated the poor condition of coldchain equipment especially at peripheral level.

"An air-conditioned vehicle is not available in the district, and the situation is not much different in other parts of the country. There are problems in collecting 
vaccines from provincial stores in ice boxes especially in summer. There is a shortage of equipment in all aspects of the cold chain including freezers/ice-lined refrigerators, cold boxes, vaccine carriers, thermometers and even ice packs. Vaccines are distributed from district stores to tehsil (sub-district) and town (rural health center) level and then to a few basic health units. The vaccines are not stored in all union councils (basic health units) and many vaccinators collect the vaccines from the rural health centre. It results in cold chain failures due to the long distance travelled by the vaccinator to reach his area. At some places, the vaccination points for a union council are made at residential/private places instead of a health facility. This also affects the cold chain as temperature and correct placement of vaccines is often neglected there. The main reasons are equipment, electricity and security problems at health facilities." - Immunization managers and providers.

The managers said that many shortcomings in resources and logistics could be addressed under the Punjab Millennium Development Goals (MDG) Program and the Punjab Health Sector Reforms Program (PHSRP) as the EPI is also a priority area in these programs. They indicated the lack of skills and authority in resource allocation and human resource management among managers. The participants highlighted limited resources for advocacy and communication campaigns at district level. They indicated that all the advocacy and communication campaigns including television and print media advertisements, brochures/posters and banners etc. are designed at central level and local communities' knowledge and attitudes are neglected in this regard. In addition, a large segment of population is missed when communication strategies are not tailored to local/district level circumstances.

\section{Technical aspects}

The participants indicated that no public health training school exists for vaccinators before their induction into the health services. Lack of regular training and essential skills among PEI/EPI staff at all levels was also highlighted.

"There is training for mid-level managers but no training program exists for district PEI/EPI supervisory and field staff. There is virtually no pre- or in-service training of vaccination staff." - Immunization managers.

"During time allocated for monthly training, the field staff has to submit their reports and administrative data so the basic purpose of training is often overlooked." Immunization providers.

The managers said that the field staff lacks very basic knowledge about polio eradication and OPV, have poor communication skills that often pose an obstacle to valid immunization coverage, and knowledge and skills to operate and maintain the cold chain is deficient. Recording and maintaining vaccine temperatures and recognizing the importance of doing so was cited as a problem in the field by the managers. The reporting and information system was considered unreliable by the managers. It was indicated by providers that managers do not stress the technical aspects. The stress is more on the administrative aspects and side issues during supervisory visits.

\section{Program operation, management and organization}

The participants indicated the need to sanction more supervisory posts and lack of public health personnel was highlighted.

"There are no sanctioned posts for the DSC and EPI Focal Person and officials are assigned these duties on a temporary basis in addition to their regular duties. The posts of DDOH are vacant in most of the Punjab. In Nankana Sahib District, the posts of DDOH in all 4 tehsils, the posts of CDCI and IV in all 4 tehsils, and the posts of ASV and TSI in 3 out of 4 tehsils are lying vacant, and officials are appointed on ad hoc basis. This is contributed to a severe lack of qualified public health personnel and poor health services structure in the country. At town (rural health centre) level, there is no official to oversee the PEI/EPI and IVs should be at each rural health centre to supervise town-level activities." - Immunization managers.

Political and bureaucratic hurdles were identified as a constraint to effectively plan and administer services by the managers. The district managers highlighted the deficient training in planning and management of the staff responsible for micro-planning. The participants stated that performance in the PEI/EPI is not discussed at monthly facility meetings. Ineffective means of performance evaluation were also indicated by the respondents.

"The current system does not have an effective means of accountability and performance-based evaluation. The annual confidential reports (ACR) system is one of the institutional tools used to gauge performance, but unfortunately it is neither annual nor confidential, resulting in a lack of confidence in the mechanism." - Immunization managers.

"Salary increments or transfer-postings are not performance-based, which affects the attitude of workers, as excellent or poor performance leads to no immediate gains or losses." - Immunization providers.

The providers indicated the problems in the vaccination area and the vaccinator's field program.

"The vaccinator usually visits a specific area once a month and there is no mechanism to cover missed children. Currently the vaccination area is based on union councils that are revenue divisions and in some cases the 
vaccinator has to cater for large populations spread over long distances. Some areas of a union council may be better covered by the nearby union council staff and vice versa." - Immunization providers.

The participants said that immunization cards are not kept safely and often mislaid by parents resulting in a lack of valid information for monitoring. No law for birth registration with a health centre and weak linkage between various health sector programs was also identified as a problem by the participants.

\section{Monitoring, evaluation and feedback}

Unreliability of reporting and poor monitoring systems was highlighted by the respondents.

"Although the monitoring for national and subnational immunization days (NIDs/SNIDs) is rigorous, routine services are neglected. A defined monitoring system from the federal to the union council level that includes a team of officials and a reporting system is in place, but the impact is not there because of a lack of coordination between central, provincial and district managers, a lack of effective supervision and motivation among staff, poor monitoring skills, unreliable reporting, poor quality of data and a lack of data use for action at all levels. The information collected is not properly used for evaluation of health facilities. The decisions to plan and prioritize immunization services are often not evidence-based." - Immunization managers.

District managers also raised concerns about confused roles and responsibilities after the decentralization of health services in 2001. They stressed that making district health departments more resourceful in policy and planning, human resource management, resource allocation, monitoring and evaluation and financial matters, and developing clear guidelines for roles and responsibilities of officials at every level from the centre to the districts may help to improve services. Table 1 presents a summary of the constraints in the PEI, as identified by the health managers and workers.

\section{Discussion}

Respondents highlighted the poor condition of the coldchain in all aspects. Previous studies have reported poor cold chain and logistics compliance [15,36-40]. Electricity and security problems at health facilities were revealed, consistent with previous studies [15,37]. An intact and efficient cold chain system is essential for quality immunization services, and problems identified in this study need to be addressed to assure that quality vaccines reach every child. A lack of resources and infrastructure is not an uncommon issue in developing countries, but poor skills and a lack of authority in resource allocation and management further aggravates the problem, as highlighted in this study. A lack of skills and authority in resource allocation and human resource management among managers was reported in a previous study in Georgia [16] and the need to train and authorize health managers in resource allocation and staffing decisions has been stressed $[16,41,42]$.

Limited advocacy and communication resources at district level were indicated in the study. Currently, all advocacy and communication campaigns, including mass media advertisements and brochures/posters are made at central level in Pakistan. These resources could be decentralized to districts so that advocacy and communication plans could be tailored to local needs. Decisions to plan and prioritize immunization services have generally not been based on studies of the populations' knowledge, attitudes and practices regarding immunization. Had the data about local communities' knowledge

Table 1 Perceptions of health workers and managers regarding constraints in the Polio Eradication Initiative

\begin{tabular}{|c|c|}
\hline Component & Major issues \\
\hline \multirow[t]{3}{*}{ Program resources and logistics } & ${ }^{*}$ Poor condition of cold chain in all aspects \\
\hline & *Poor skills and authority in resource allocation and human resource management \\
\hline & *Limited advocacy and communication resources \\
\hline Technical aspects & *Deficient skills and training among staff at all levels in almost all aspects of the program \\
\hline \multirow[t]{8}{*}{ Program operation, management and organization } & *Deficiency of public health professionals and poor health services structure \\
\hline & ${ }^{*}$ Administrative issues including: \\
\hline & *ineffective means of performance evaluation, \\
\hline & *bureaucratic and political influences, \\
\hline & *problems in vaccination area and field program, \\
\hline & *lack of immunization cards, \\
\hline & ${ }^{*}$ no birth records at health facilities, and \\
\hline & *poor linkage between different preventive programs \\
\hline \multirow[t]{3}{*}{ Monitoring, evaluation and feedback } & *Unreliable reporting and poor monitoring systems \\
\hline & *Limited use of local data for interventions \\
\hline & *Unclear roles and responsibilities after decentralization \\
\hline
\end{tabular}


and practices been generated and used, advocacy and communication interventions could have been more effective in reaching zero-dose children [43].

A lack of public health training schools and training programs for vaccination staff, deficient knowledge and skills among staff at all levels in the PEI/EPI in almost all aspects of the program, and deficient knowledge of staff in communication skills were highlighted in the study. Previous studies show that the knowledge gaps underlie low compliance with the vaccination schedules $[44,45]$ and the quality of interaction between health workers and caregivers is decisive to ensure completion of the vaccination schedule [46-48]. Interventions aimed at fostering the communication skills of health workers and community outreach can significantly improve immunization coverage, as shown in previous international studies [49-51]. Capacity building of staff and both pre- and in-service training programs are essential to the success of the program. It was indicated that supervision is often focused on administrative rather than technical aspects, and this negatively affects providers' motivation and performance [41].

A deficiency of public health professionals and poor health services structure, administrative issues, including ineffective means of performance evaluation, bureaucratic and political influences, problems in vaccination areas and vaccinators' field programs, no birth records at health facilities, and poor linkage between different preventive programs were highlighted in the study. Poor work organization, and weak management structures and practices especially at peripheral level have been reported previously [16]. Without improving the public health services structure, the success of any preventive program seems elusory. There is a need to develop structures, processes and the skills of the existing workforce and authorize and train health managers in resource management [16]. Political and bureaucratic influences hinder effective planning and administration of services and usually there is undue interference in the transfer-postings of staff $[18,52]$. The need for other health programs to collaborate with immunization programs has been stressed previously. In particular, Lady Health Workers (LHWs) working under the National Program for Family Planning and Primary Health Care (NP for FP \& PHC) can be deputed with vaccinators to improve immunization coverage $[18,53]$.

The unavailability of immunization cards and deficient knowledge among parents to keep cards safely was also indicated. The lack of immunization cards has been indicated in previous studies [17,54-57]. A national vaccination card program could significantly increase coverage, especially its validity, and the cost of developing such a program would be offset by the savings resulting from not vaccinating children who are already up to date with their vaccinations [58].

The deficient knowledge of staff about monitoring, poor reporting compliance, and limited use of local data for interventions was highlighted. Previous studies have also reported problems in data quality and validity [15,26,59-63]. The lack of supervision and knowledge among responsible staff has been indicated previously [64]. In Pakistan, EPI records are not computerized and a previous study had shown the feasibility of a linked database system for immunization [65]. The data quality audits conducted in 27 countries, including Pakistan, revealed weaknesses in monitoring systems at all levels [61]. There is a need to see the quality of data and monitoring systems in a broader perspective, not only focusing on technicalities but also on support mechanisms $[62,66,67]$. Supportive supervision is critical in strengthening and enhancing performance at health facilities regarding polio eradication $[26,68,69]$. Previous experiences have shown significant improvements in data quality and monitoring systems as a result of data quality self-assessment and the use of data for action [70-72], and this strategy is also recommended in the Reaching Every District (RED) approach and the Global Framework for Immunization Monitoring and Surveillance (GFIMS) by the World Health Organization $[72,73]$. It was indicated that decentralization has resulted in unclear roles and responsibilities which are adversely affecting health system performance, accountability and staff motivation. Similar results have been reported in many previous studies [16,41,74-76].

The study was based on qualitative data that might be a limitation in itself. However, qualitative research can yield very useful information for action especially in disease specific programs [24-31]. The study did not follow a pre-existing conceptual framework but the findings provide a baseline picture of deficiencies. The paper describes the qualitative part of the in-depth PEI evaluation in a district and the consistency of the results with the quantitative part of the project provides additional evidence of validity [15]. Reporting bias may have confounded some of the responses, but previous studies report similar issues suggesting that results are externally valid $[16,77]$. Although the study was conducted in a rural district of Pakistan's Punjab province, the findings may be generalized to other rural areas in Pakistan in particular and South Asia in general, due to similar health system infrastructures, socio-cultural environments and topography. We recommend further studies to evaluate the findings of the study, for example, supportive supervision, immunization service crash programs involving some administrative measures within the current infrastructure, giving authority to districts in 
resource management etc., which can be further evaluated by cluster-control trials and pilot projects at district level.

\section{Conclusions and Recommendations}

Perceptions of the field personnel who are actually involved in program execution render an invaluable insight into constraints, and guide policy makers to institute practical interventions. Shortcomings and bottlenecks in the PEI highlighted in the study are potentially important due to the failure to achieve polio eradication despite continuous efforts by the global community over the past two decades, and these should be considered in prioritizing future strategies. Based on the opinions and views of health managers and workers in the PEI/EPI in a district, the following recommendations may help to improve polio eradication efforts in the region:

- Cold chain equipment should be updated and maintained on a regular basis. Air-conditioned vehicles should be made available in all district headquarters. Electricity and security problems should be addressed and the vaccination point for a union council should be at the respective health centre. Reserve stocks of essential EPI equipment and supplies should be maintained at the district stores.

- District health managers should be authorized and trained in resource allocation and human resource management.

- Advocacy and communication resources should be decentralized and districts should design their advocacy, communication and social mobilization strategies according to the local circumstances.

- There should be training schools for vaccination staff, before their induction in each district. These schools could also be used for further training of PEI/EPI staff, which should be mandatory for their promotion. Focused training programs, held biannually, should be initiated for PEI/EPI staff at all levels. All relevant staff should be trained in face-toface individual and group communication skills, and in techniques for using printed material with the clients.

- District health departments should be authorized to make resource management and staffing decisions. The provision of incentives to young medical graduates for joining public health services and establishing national public health services is also recommended.

- Administrative measures, including appraisal of excellent performance, redefining vaccination areas based on a 10 kilometers radius and/or 15,000 inhabitants rather than revenue circles, and making flexible vaccination field plans should be instituted. The posts of DSC and EPI Focal Person in a district and IVs in rural health centers should be sanctioned. A law for birth registration with health facilities should be constituted and a birth register should be maintained by Lady Health Visitors. This could significantly increase OPV zero-dose coverage. The linkage between preventive programs should be improved. In Nankana Sahib District a unique model of multi-purpose health workers is being followed where EPI, CDC and sanitation staff is working together for PEI/EPI activities, and this could be done in other districts of Punjab, ensuring that equal incentives are offered to all the staff working for the PEI/EPI. A national immunization card crash program should be initiated. There should be a mechanism in place to ensure accessibility of immunization cards to vaccinators and monitoring personnel, and immunization cards could be declared mandatory for admission to the schools.

- The staff at all levels in the PEI/EPI should be trained to improve monitoring, data quality assessment and the use of data for action. Staff should be encouraged to do realistic reporting, and records should be computerized and integrated with the district health management information system (DHMIS).

- District health departments should be made more resourceful in monitoring, evaluation, and financial matters and clear guidelines for the roles and responsibilities of officials at every level from the centre to the districts should be developed.

\section{Acknowledgements}

Mushtaq MU would like to dedicate the entire work to the sweet memories of our co-author Ubeera Shahid (April 04, 1987-February 10, 2010), who left us deeply saddened in an unfortunate highway car accident. She was a great human being, a fourth year medical student and a brilliant young researcher, and meant so much to us. She'll always live in our hearts and prayers.

We are highly grateful for the valuable comments of Laura Esmail and Mamuka Djibuti, and the editorial team on the earlier version of the manuscript. We would like to thank Dina Kakar, MD, MSc for her invaluable efforts. We are indebted to the staff of Department of Health, District Nankana Sahib, in particular Liaqut Virk, Riaz Ahmad and Mukhtar Dogar. We acknowledge the untiring efforts of our research associates especially Mohsin Z S Ullah, Usman Khurshid, Hussain M Abdullah, M Waqas, Waqar Ahmad, M Qais Luqman, M Rizwan, Fatima Omer, Anum Saeed and Komal Mushtaq. We also thank volunteers who worked with us especially $\mathbf{M}$ Hammad Mushtaq and Hammas Liaqut. Mushtaq MU likes to thank Andrea Lyman, MD, MS, Janelle Anderson, MPH and Douglas Proops, MD, MPH

We acknowledge partial financial support from Allama labal Medical College, Lahore, Pakistan and assistance from Department of Health, District Nankana Sahib.

\section{Author details}

${ }^{1}$ Research Society, Allama labal Medical College, Lahore, Pakistan.

2Department of Health, Government of Punjab, Lahore, Pakistan. 


\section{Authors' contributions}

All authors contributed significantly in all phases of the project in accordance with uniform requirements established by International Committee of Medical Journal Editors (ICMJE) and contributors who do not meet authorship criteria are listed in acknowledgements. All authors have read and approved the final version of manuscript.

\section{Competing interests}

The authors declare that they have no competing interests.

Received: 31 July 2009 Accepted: 23 August 2010

Published: 23 August 2010

\section{References}

1. History. Global Polio Eradication Initiative, World Health Organization. [http://www.polioeradication.org/history.asp].

2. Resolution WHA 41.28: Global eradication of poliomyelitis by the year 2000. Handbook of resolutions and decisions of the World Health Assembly and the Executive Board Geneva, Switzerland: World Health Organization, 3 1993, III, (1985-92).

3. World Health Organization: Global Polio Eradication Initiative: strategic plan 2004-08. WHO, Geneva 2003.

4. World Health Organization: Global Polio Eradication Initiative: annual report 2006. WHO, Geneva 2007, (WHO/Polio/07.02).

5. World Health Organization: Global Polio Eradication Initiative: annual report 2007. WHO, Geneva 2008, (WHO/Polio/08.02).

6. Polio case count. Global Polio Eradication Initiative, World Health Organization. [http://www.polioeradication.org/casecount.asp].

7. World Health Organization (WHO): World health statistics 2009. WHO, Geneva 2009.

8. United Nations Children's Fund (UNICEF): The state of world's children 2009. UNICEF, New York 2009.

9. National Reconstruction Bureau, Government of Pakistan: Local government plan 2000. Islamabad, Pakistan 2000.

10. Expanded Programme on Immunization. National Institute of Health, Ministry of Health, Government of Pakistan. [http://www.nih.org.pk].

11. Polio eradication. Eastern Mediterranean Regional Office, World Health Organization. [http://www.emro.who.int/polio/].

12. Update on Polio eradication in Pakistan. Eastern Mediterranean Regional Office, World Health Organization. [http://www.emro.who.int/pakistan/pdf/ polio_brief.pdf].

13. AFP/polio case count. Global Polio Eradication Initiative, World Health Organization. [http://www.who.int/immunization_monitoring/en/diseases/ poliomyelitis/case_count.cfm].

14. Kroeger A: Response errors and other problems of health interview surveys in developing countries. World health statistics quarterly 1985, 38:15-37.

15. Mushtaq MU, Majrooh MA, Ullah MZ, Akram J, Siddiqui AM, Shad MA, Waqas M, Abdullah HM, Ahmad W, Shahid U, Khurshid U: Are we doing enough? Evaluation of the polio eradication initiative in a district of Pakistan's Punjab province: a LQAS study. BMC Public Health 2010, 10:60

16. Esmail LC, Cohen-Kohler JC, Djibuti M: Human resource management in the Georgian National Immunization Program: a baseline assessment. Human Resources for Health 2007, 5:20.

17. The Consultants Consortium, SoSec KEMC: Report: Third Party Evaluation of Expanded Programme on Immunization Punjab. Lahore, Pakistan 2000.

18. Mangrio NK, Alam MM, Shaikh BT: Is Expanded Programme on Immunization doing enough? Viewpoint of Health workers and Managers in Sindh, Pakistan. J Pak Med Assoc 2008, 58(2):64-67.

19. Mansuri FA, Baig LA: Assessment of immunization service in perspective of both the recipients and the providers: a reflection from focus group discussions. J Ayub Med Coll Abbottabad 2003, 15:14-8

20. Dietz V, Cutts F: The use of mass immunization campaigns in expanded programme on immunization: a review of reported advantages and disadvantages. Int J Health Serv 1997, 27:767-90.

21. Fitzpatrick R, Boulton M: Qualitative methods for assessing health care. Quality in Health Care 1994, 3:107-113.

22. National Institute of Population Studies (NIPS): Pakistan and Macro International Inc. Pakistan Demographic and Health Survey 2006-07 Islamabad, Pakistan 2008
23. Administrative data. Department of Health, Government of Punjab. [http://www.punjab.gov.pk/].

24. O'Cathain A, Murphy E, Nicholl J: Why, and how, mixed methods research is undertaken in health services research in England: a mixed methods study. BMC Health Services Research 2007, 7:85.

25. Pope C, Mays $N$ : Reaching the parts other methods cannot reach: an introduction to qualitative methods in health and health services research. British Medical Journal 1995, 311:42-45.

26. McDowell I, MacLean L: Blending qualitative and quantitative study methods in health services research. Health Informatics Journal 1998, 4:15-22.

27. Campbell M, Fitzpatrick R, Haines A, Kinmonth AL, Sandercock P, Spiegelhalter D, Tyrer P: Framework for design and evaluation of complex interventions to improve health. British Medical Journal 2000, 321:694-696.

28. Fulop N, Allen P, Clarke A, Black N: Issues in studying the organization and delivery of health services. In Studying the organization and delivery of health services Research methods. Edited by: Fulop N, Allen P, Clarke A, Black N. London: Routledge; 2001.

29. Murphy E, Dingwall R, Greatbatch D, Parker S, Watson P: Qualitative research methods in health technology assessment: a review of the literature. Health Technology Assessment 1998, 2(16):1-274.

30. Bryman A: Quantitative and qualitative research: further reflections on their integration. In Mixing methods: qualitative and quantitative research. Edited by: Brannen J. Aldershot: Ashgate; 1992:57-78.

31. Parry-Langdon N, Bloor M, Audrey S, Holliday J: Process evaluation of health promotion interventions. Policy \& Politics 2003, 31(2):207-216.

32. Crabtree B, Miller W: Doing qualitative research: multiple strategies. London: Sage 1993.

33. Silverman D: Interpreting qualitative data. London: Sage 1993.

34. Bryman A, Burgess R: Analysing qualitative data. London: Routledge 1993.

35. Strauss A: Qualitative analysis for social scientists. Cambridge: Cambridge University Press 1987.

36. Suraratdecha C, Ramana CBSV, Kaipilyawar S, Krishnamurthy JVG, Sivalenka S, Ambatipudi N, Gandhi S, Umashankar K, Cheyne J: Cost and effectiveness analysis of immunization service delivery support in Andhra Pradesh; India. Bull World Health Organ 2008, 86:221-28.

37. Samant Y, Lanjewar H, Parker D, Block L, Tomar GS, Stein B: Evaluation of the Cold-Chain for Oral Polio Vaccine in a Rural District of India. International Observer Public Health Reports 2007, 122:112-21.

38. Goel NK, Swami HM, Bhatia SP: Evaluation of cold chain system in Chandigarh during PPI campaign 2001-02. Indian J Public Health 2004, 48:200-4.

39. Aggarwal A, Singh AJ: Evaluation of cold chain system in rural areas of Haryana. Indian Pediatr 1995, 32:31-4.

40. Miller NC, Harris MF: Are childhood immunization programmes in Australia at risk? Investigation of the cold chain in the Northern Territory. Bull World Health Organ 1994, 72(3):401-408.

41. World Health Organization: The World Health Report 2006: working together for health. WHO, Geneva 2006.

42. Kolehmainen-Aitken RL: Decentralization's impact on the health workforce: perspectives of managers, workers and national leaders. Human Resources for Health 2004, 2:5.

43. Waisbord S: Assessment of Communication Programs In Support of Polio Eradication: Global Trends and Case Studies. Washington, DC: The CHANGE Project Academy for Educational Development/The Manoff Group 2004

44. Harmanci H, Gurbuz Y, Torun SD, Tumerdem N, Erturk T: Reasons for nonvaccination during national immunization days: a case study in Istanbul, Turkey. Public Health 2003, 117(1):54-61.

45. Bond L, Nolan T, Pattison P, Carlin J: Vaccine preventable diseases and immunizations: A qualitative study of mothers' perceptions of severity, susceptibility, benefits and barriers. Australian/New Zealand Journal of Public Health 1998, 22(4):441-6.

46. Basic Support for Institutionalizing Child Survival (BASICS), United Nations Children's Fund (UNICEF) and World Health Organization WHO: Communication for Immunization and Polio Eradication. Joint Case Studies Washington, DC 1999.

47. Berhane Y, Pickering J: Are reminder stickers effective in reducing immunization dropout rates in Addis Ababa, Ethiopia? Journal of Tropical Medicine \& Hygiene 1993, 96(3):139-145. 
48. Bhattacharyya K, Shafritz L, Graeff J: Sustaining health workers' performance in Burkina Faso. Washington, DC: Basic Support for Institutionalizing Child Survival (BASICS) 1994.

49. Briss PA, Rodewald LE, Hinman AR, Shefer AM, Strikas RA, Bernier RR, Carande-Kulis VG, Yusuf HR, Ndiaye SM, Williams SM: Reviews of evidence regarding interventions to improve vaccination coverage in children, adolescents and adults. Am J Prev Med 2000, 18:97-140.

50. LeBaron CW, Starnes D, Dini EF, Chambliss JW, Chaney M: The impact of interventions by a community-based organization on inner-city vaccination coverage. Fulton County; Georgia; 1992-93. Arch Pediatr Adolesc Med 1998, 152:327-32.

51. Barnes K, Friedman SM, Namerow PB, Honig J: Impact of community volunteers on immunization rates of children younger than 2 years. Arch Pediatr Adolesc Med 1999, 153:518-524.

52. Bonu S, Rani M, Baker $\mathrm{T}$ : The impact of national polio immunization campaign on levels and equity in immunization coverage: evidence from rural North India. Soc Sci Med 2003, 57:1807-19.

53. Loevinsohn B, Hong R, Gauri V: Will more inputs improve the delivery of health services?: Analysis of district vaccination coverage in Pakistan. Int $J$ Health Plann Manage 2006, 21:45-54.

54. Cakir B, Uner S, Temel F, Akin L: Lot quality survey: an appealing method for rapid evaluation of vaccine coverage in developing countries experience in Turkey. BMC Public Health 2008, 8:240.

55. Ramakrishnan R, Rao TV, Sundaramoorthy $L$, Joshua V: Magnitude of recall bias in the estimation of immunization coverage and its determinants. Indian Pediatr 1999, 36(9):881-5.

56. Odusanya OO, Alufohai EF, Meurice FP, Ahonkhai VI: Determinants of vaccination coverage in rural Nigeria. BMC Public Health 2008, 8:381.

57. Chhabra P, Nair P, Gupta A, Sandhir M, Kannan AT: Immunization in urbanized villages of Delhi. Indian J Pediatr 2007, 74:131-4.

58. Valadez JJ, Wel LH: Maternal Recall Error of Child Vaccination Status in a Developing Nation. Am J Public Health 1992, 82(1):120-22.

59. Diko M, Oni AQO, Ganivet S, Kone S, Pierre L, Jacquet B: Safety of immunization injections in Africa: not simply a problem of logistics. Bull World Health Organ 2000, 78(2):163-69.

60. Murray CJL, Shengelia B, Gupta N, Moussavi S, Tandon A, Thieren M: Validity of reported vaccination coverage in 45 countries. Lancet 2003, 362:1022-7.

61. Ronveaux O, Rickert D, Hadler S, Groom H, Lloyd J, Bchir A, Birmingham M: The immunization data quality audit: verifying the quality and consistency of immunization monitoring systems. Bull World Health Organ 2005, 83(7):503-10.

62. Mavimbe JC, Braa J, Bjune G: Assessing immunization data quality from routine reports in Mozambique. BMC Public Health 2005, 5:108.

63. Onta SR, Sabroe S, Hansen EH: The quality of immunization data from routine primary health care reports: a case from Nepal. Health Policy and Planning 1998, 13:131-9.

64. Loevinsohn BP: Data utilizatioin and analytical skills among mid-level health programme managers in a developing country. Int J Epidemiol 1993, 23:194-200.

65. Ali M, Do CG, Clemens JD, Park JK, Seidlein LV, Truong MT, Vu TD, Le TH, Dang TD: The use of a computerized database to monitor vaccine safety in Viet Nam. Bull World Health Organ 2005, 83(8):604-10.

66. Freund PJ, Kalumba K: Monitoring and evaluation of primary health care in rural Zambia. A comparative study. Scand J Soc Med 1985, 13:137-146.

67. Sorensen HT, Sabroe S, Olsen J: A framework for evaluation of secondary data sources for epidemiological research. Int J Epidemiol 1996, 25:435-442.

68. World Health Organization: Supportive supervision [presentation]. Meeting of the GAVI Implementation Task Force on Supportive Supervision: 15-17 October 2002; Geneva, Switzerland Geneva 2002.

69. Marquez L, Kean L: Making supervision supportive and sustainable: new approaches to old problems. Maximizing Access and Quality (MAQ) Initiative paper No. 4 Washington, DC 2002.

70. Streefland PH: Enhancing coverage and sustainability of vaccination programs: an explanatory framework with special reference to India. Soc Sci Med 1995, 41:647-656.

71. Weeks RM, Svetlana F, Noorgoul S, Valentina G: Improving the monitoring of immunization services in Kyrgyzstan. Health Policy Plan 2000, 15:279-86
72. Department of Immunization, Vaccines and Biologicals, World Health Organization: Increasing immunization coverage at the health facility level. Geneva 2002, (WHON\&B/02.27).

73. Dabbagh A, Eggers R, Cochi S, Dietz V, Strebela P, Cheriana T: A new global framework for immunization monitoring and surveillance. Bull World Health Organ 2007, 85(12):904-05.

74. Buchan J: What difference does ("good") HRM make? Human Resources for Health 2004, 2:6.

75. Dussault G, Dubois CA: Human resources for health policies: a critical component in health policies. Human Resources for Health 2003, 1:1.

76. Bach S: HR and new approaches to public sector management: improving HRM capacity. Workshop on Global Health Workforce Strategy Annecy, France: World Health Organization 2000.

77. Figueras J, McKee M, Lessof S: Ten years of health sector reform in CEE and NIS: an overview. Background paper prepared for USAID conference: 2931 July 2002; Washington DC Washington DC 2002

Pre-publication history

The pre-publication history for this paper can be accessed here: http://www.biomedcentral.com/1472-698X/10/22/prepub

doi:10.1186/1472-698X-10-22

Cite this article as: Mushtaq et al:: From their own perspective constraints in the Polio Eradication Initiative: perceptions of health workers and managers in a district of Pakistan's Punjab province. BMC International Health and Human Rights 2010 10:22.

\section{Submit your next manuscript to BioMed Central and take full advantage of:}

- Convenient online submission

- Thorough peer review

- No space constraints or color figure charges

- Immediate publication on acceptance

- Inclusion in PubMed, CAS, Scopus and Google Scholar

- Research which is freely available for redistribution

Submit your manuscript at www.biomedcentral.com/submit
C) Biomed Central 